\title{
Familial benign chronic pemphigus
}

\author{
INSERM
}

\section{Source}

INSERM. (1999). Orphanet: an online rare disease and orphan drug data base. Familial benign chronic pemphigus. ORPHA:2841

Benign chronic familial pemphigus of Hailey-Hailey is characterized by rhagades mostly located in the armpits, inguinal and perineal folds (scrotum, vulva). 